\title{
Beyond a constructivist curriculum : a critique of competing paradigms in music education
}

Article

Accepted Version

Garnett, J. (2013) Beyond a constructivist curriculum : a critique of competing paradigms in music education. British Journal of Music Education, 30 (2). pp. 161-175. ISSN 02650517 doi: https://doi.org/10.1017/S0265051712000575 Available at https://centaur.reading.ac.uk/29863/

It is advisable to refer to the publisher's version if you intend to cite from the work. See Guidance on citing.

To link to this article DOI: http://dx.doi.org/10.1017/S0265051712000575

Publisher: Cambridge University Press

All outputs in CentAUR are protected by Intellectual Property Rights law, including copyright law. Copyright and IPR is retained by the creators or other copyright holders. Terms and conditions for use of this material are defined in the End User Agreement.

www.reading.ac.uk/centaur

\section{CentAUR}


Central Archive at the University of Reading

Reading's research outputs online 


\title{
Beyond a constructivist curriculum: A critique of competing paradigms in music education
}

\begin{abstract}
The distinction between learning to perform on an instrument or voice and learning music in a wider sense is one that is made in many countries, and is especially pertinent in England in the context of recent policy developments. This article argues that, whilst this distinction has come to represent curricula based on the opposing paradigms of behaviourist and constructivist approaches to learning, this opposition does not necessarily extend to the pedagogy through which the curricula are taught. A case study of the National Curriculum in England highlights the characteristics of a curriculum based on constructivist principles, along with the impact this has when taught in a behaviourist way. It is argued that conceiving the curriculum in terms of musical competencies and pedagogy in terms of musical understanding would provide a basis for greater continuity and higher quality in the music education experienced by young people.
\end{abstract}

In 2010 England's then new Secretary of State for Education, Michael Gove, initiated a review of music education that highlighted the government's priority that every child should have the opportunity to learn to play an instrument and sing (Henley 2011). This shone a spotlight on a fault line that runs through music education, not only in England, but in many countries around the world: the distinction that is made between learning to perform and learning music in a wider sense. In England, this has been in part an institutional distinction, with Local Authority music services (now music hubs) and conservatoires primarily concerned with teaching instruments and singing, and schools and university music departments primarily teaching "music". This institutional distinction plays out in the distinction between a curriculum based on learning particular musical skills (primarily performing, but also composing and studio production for example) and a curriculum in which the principal focus is on cultural, contextual and theoretical knowledge (in which composition also plays a part). Behind these differences in practice is an ideological distinction, however, that reveals two fundamentally different paradigms of education. One is a paradigm based on behaviourist psychology, in which learning music consists of becoming proficient in a range of musical behaviours or skills. The other paradigm is based on constructivist psychology, and considers musical learning to be essentially to do with cognitive development. This article will argue that these distinctions of practice and paradigm do not simply align with one another, but that both performance and "academic" curricula can be founded on either a behaviourist or constructivist 
paradigm. In doing so, it will offer a critique of the way in which the constructivist paradigm has been manifest in thinking about the school curriculum, and particularly in England's National Curriculum.

\section{Learning an instrument}

On the face of it, the difference between instrumental lessons and classroom music lessons is a matter, on the one hand, of curriculum content, and on the other of mode of delivery. Instrumental lessons teach performance on a particular instrument, archetypally based on a one-to-one model; whereas in classroom music lessons, performance is only one element of what is taught in a one-tomany model. However, the approach to curriculum music in England has developed not just in response to the different circumstances of the classroom, but reflects a fundamental rejection of the values on which instrumental tuition has been based.

The origins of this conflict are to be found in the creative approach to the classroom curriculum that was developed by John Paynter in his work at the University of York and later through the Schools Council. Within the context of its day, the conflict was initially expressed slightly differently and rather more widely. It was articulated as the difference between a subject-centred model of music education that represented the skills, literacy and values of Western art music and a child-centred model that encompassed experiment, creativity and contemporary developments in music (Cox 2001). The child-centred model was a form of aesthetic education that acknowledged and valued children's capacity to express their perceptions and insights (Finney 2011). Its purpose was to enhance children's ability to make informed, interpretative judgements using musical material. Whilst this required children to have the skills to form and manipulate music, the focus was on "using the skills they have acquired as they acquire them" (Paynter 1982, p.123). Indeed, with an emphasis on creativity rather than composition, music was considered primarily in terms of personal expression rather than the technique through which that expression might be realised.

The effect of placing children's aesthetic self expression at the centre of music education was not just to promote the activity of creative music making, but also to reject approaches to teaching that involved transmitting pre-existing knowledge or encouraging children to reproduce pre-defined musical responses. "Paynter's chief enemy was music education reduced to a narrow course of musical training where tutored skills and proficiencies dominated to the exclusion of imagination and creativity" (Finney 2011, p. 56). The issue at stake was not just the content of the teaching, but the very approach to teaching: training in the skills of composition would have been equally 
abhorrent to Paynter as training in performing skills. Music education involved the personal and aesthetic growth of the child.

The distinction between training and education reflects the difference between learning based on acquiring specific behaviours and that based on developing understanding. Glaserfeld (1995a) characterises training as modifying behavioural responses whilst leaving comprehension to fortuitous accidents. The key limitation of training, in this view, is manifest in the extent to which an individuals are able to adapt their responses when faced with new circumstances. To do so requires the ability to make transferrable generalisations from experience (Soloman 2003) and this is a matter of cognition and meta-cognition rather than one of reproducing a learned response to a specific stimulus (William \& Burden 1998). If training results in the ability to reproduce a behaviour in response to a stimulus, education is regarded as developing the ability to adapt behaviour by applying understanding to new situations. The extent of this divergence in values is expressed succinctly by Glaserfeld (1995a, p4) “...a philosophy of education that believes in teaching the right answers is not worth having."

Paynter developed his creative approach in response to the context of classroom teaching, not as a critique of instrumental teaching. However, the effect was to distinguish between a generalist music education that aimed to develop the whole person and a specialist form of music education that aimed to develop the techniques of playing an instrument for a gifted few (Aston \& Paynter 1970). This placed instrumental teaching firmly in the category of training. As Fautley puts it, "...it could be considered that learning to play a musical instrument according to the typical Western model of practise and refinement is exemplification on a large scale of behaviourist principles" (Fautley 2010, p. 44). This training is characterised by the specific goal of achieving technical mastery on a particular instrument. It involves a hierarchy of value predicated on progressive technical competence (exemplified by the graded exams of the Associated Board of the Royal Schools of Music). It is characterised by the subordination and separation of musical skills that are not directly involved with to performance (such as aural perception and knowledge of musical rudiments Fautley 2010). Learning an instrument thus became regarded as training in the sense that was described above by Glaserfeld: the acquisition of specific musical behaviours, involving the transmission of musical skills from teacher to pupil. Instrumental teaching became associated with training performers rather than educating musicians.

However, learning an instrument is not intrinsically and fundamentally wedded to the behaviourist paradigm, but can provide a medium for learning that is primarily concerned with developing an understanding of music. This is apparent, for example, in the evaluation of whole-class instrumental 
tuition in English schools by Bamford and Glinkowski (2010). In their observations of teaching, they identified a diversity of espoused aims. In some cases, teachers did set out to teach instrumental technique - to develop the particular set of skills in the children that would enable them to play the violin, guitar, or bassoon. In other cases, however, the teachers' aim was that children should acquire musical learning through the process of learning the particular instrument. In these lessons, there was less emphasis on technical progression and more on general musicianship and the creative exploration of sound through the instrument. The instrument was the medium for cognitive and affective learning to do with how sounds are produced, organised, shaped and combined, rather than an end in itself.

A similar distinction between approaches to instrumental tuition can be found in Reid's study of conservatoire students (Reid 2001). She divided approaches to learning an instrument into five categories. At one extreme was a focus on the instrument, with technical mastery as the principal aim and examination success the primary outcome. At the other end of the spectrum was a focus on expressing meaning, with issues of interpretation setting the agenda for technical development and meaningful performance the primary outcome. Whereas students in the first category were learning within a paradigm in which musical expression was a by-product of skill acquisition, for those in the fifth category, meaning and expression were the main focus of learning, and technical proficiency was the means of realising the performer's cognitive intention.

Learning to play the violin is one example of a curriculum for music education. Learning to sing, learning to compose, learning studio sound production are others. These can be taught within a behaviourist paradigm that focuses on the development of skill because it regards learning as an alteration in behaviour and considers cognitive processes to be beyond the reach of direct intervention. They can also be taught within a constructivist paradigm that prioritises the development of understanding because it considers that the mind controls musical activity and that learning will be more efficient if it is based on the cognitive structures behind musical experiences rather than on those experiences themselves. A curriculum based on learning an instrument cannot therefore be dismissed solely on the basis of a critique of the behaviourist paradigm. Conversely, a critique of the behaviourist paradigm is not the same things as a critique of instrumental teaching: the paradigm might equally well be used as the basis for teaching other forms of curriculum, as we shall see. 


\section{Learning music}

Having established that a curriculum based on acquiring musical behaviours need not be taught in a behaviourist way, let us now return to the creative musical curriculum of Paynter to consider in more detail the nature of a curriculum that is based on constructivist principles. Some disciplines have been explicit in their espousal of the constructivist paradigm. For example Teaching Games for Understanding is a movement within physical education that has re-conceptualised the way that sports are taught in order to focus on the development of strategic thinking and the understanding of tactics rather than on skill development. Students are exposed to similar tactical structures in a variety of different games in order to develop their capacity to make decisions, and underpin their skill development with an understanding of how to deploy their skills (Griffin \& Patton 2005). In music, as we have seen, the constructivist paradigm took root through the introduction of creativity to the curriculum, and has remained largely implicit. Nevertheless, through the work of Paynter and its theorisation by Swanwick (for example Swanwick 1979), as well as through wider, non-musical educational influences on the curriculum, it has informed the development of the National Curriculum for music in England. In what follows I will take an analytical rather than an historical approach to identify five key constructivist features of the curriculum. (Accounts of the introduction and development of the National Curriculum can be found in Pitts 2000, Cox 2002 and Finney 2011.)

The principal feature of a curriculum based on constructivist principles is that it defines learning in terms of what students understand rather than in terms of what they can do. Initially, this had not been the case for the National Curriculum in music, which expressed learning in terms of musical activities: performing and composing, listening and appraising (DES 1992, DFEE 1995). However, the revision of the curriculum that was introduced in 2000 resulted in a single attainment target for music in which the activities of performing, composing and listening were directed towards the development of musical understanding (QCA 1999). This begged the important question of what musical understanding involved. The curriculum provided at least an implicit answer to this question in the form of descriptors for levels of attainment. Whereas with the introduction of the National Curriculum in 1992 the decision had been taken that art, PE and music could not be assessed in the same way as other subjects (Dearing 1994), the system of National Curriculum levels of attainment (Levels 1 to 8 plus Exceptional Performance) was now extended to include them. The descriptors for each level presented a progressive model for the outcomes of the curriculum, the first sentence summarising the characteristics of understanding (for example, at Level 5, "Pupils identify and explore musical devices and how music reflects time, place and culture." QCA 2007) and the remainder providing illustrations of how students would demonstrate their understanding (QCA 
2004a). The nature of musical understanding and its role within the curriculum was clarified further by the Key Stage 3 National Strategy for music, which interpreted and expanded upon the National Curriculum in the form of a professional development course for teachers. This expressed clearly for the first time the way in which musical understanding, as conceived in the National Curriculum, arose from knowledge of musical features, the experience of these features through the development of musical skills, and an appreciation of the social context of music (National Strategy 2006). Whilst the nature of musical understanding is open to debate (see below) the significant point for the moment is that the National Curriculum, supported by the National Strategy, defined the nature of musical learning in the classroom in terms of cognitive development rather than skill acquisition.

Engagement in musical activity nevertheless remained fundamental to learning, because it was through encounters with music that students would develop their understanding. The constructivist paradigm presents a model of learning in which individuals construct a mental representation of the world in which their existing mental schemata are tested and adapted through experience and through interaction with other people (Glaserfeld 1995b). This supports a student-centred curriculum based on active learning, because understanding cannot be passed from the teacher to the pupil; it must be built up individually by each learner on the basis of his or her experience (Glaserfeld 1995a). In the 2007 revision of the National Curriculum, performing, composing and listening are described as "Key processes", alongside reviewing and evaluating. Students are presented with opportunities to learn by listening to and playing examples of music, exploring its characteristics through composition, and evaluating the results (QCA 2007). This combination of activities has its origin in Swanwick's "C(L)A(S)P” model of musical knowledge (Swanwick \& Taylor 1982) in which Audition (ie listening) is central, bounded by Composition and Performance, and supported by Literature of an and about music along with elements of Skill acquisition. However, the principle on which the CLASP model is based is one articulated by Paynter, "The sound comes first" (Paynter \& Aston 1970, p. 14), and later theorised by Odam (1995). This grounds musical learning in the experience and manipulation of musical sound through performing and composing and not in the transmission of notation and theory as an a priori expression of musical knowledge.

A third, distinctively constructivist feature of the National Curriculum is that the musical activities of performing, composing and listening on which the curriculum is based are conceived of as being integrated with one another. Indeed, this integration of practice is one of four "Key Concepts" in the 2007 revision of the curriculum (QCA 2007). This is significant, because it emphasises that performing, composing and listening are not to be regarded as musical skills to be developed in their 
own right. Students are not to be assessed on performance or composition or listening, but on their understanding as it is evinced through the combination of these activities (Fautley 2010). Indeed, Paynter (1997) considered the curriculum to make sense only if these three elements are seen as "diversifying an essential unity of creative musical thought." (p. 19). Composing and performing and listening are thus different manifestations of musical thought, complementary experiences though which students can, on the one hand, extend their understanding of the way in which music works and, on the other, demonstrate the extent of their understanding. The combination of activities is potent because it requires students to transfer learning from one medium to another: patterns that are heard are enacted through performance and recreated through composition; patterns that are composed are exemplified through performance and evaluated through listening. Constructivism regards cognition as the individual's attempt to organise the experiential world, and learning depends on the ability to transfer mental representations of the world from one situation to another, adjusting them to accommodate the world when they do not fit (Glaserfeld 1995b). Approaching musical phenomena though performance, composition and listening thus enables students to triangulate their understanding, validating or adjusting the mental representations of music they have developed through one activity by applying them in another. "Integration is important because it enables children to understand how different musical encounters relate to each other and how each contributes to their developing relationship with, and knowledge of, music" (Spruce 2011, p. 63).

Fourth, the development of musical understanding arises not just from encounters with different forms of musical thinking (composing, performing, listening) but also with different types of music. Thus the National Curriculum requires students to study music from a range of traditions, styles and genres in order to understand the different ways in which the elements of music are employed, but also to perceive commonalities in the way that sound is manipulated. This is expressed in the "Key Concepts" of cultural understanding and critical understanding (QCA 2007). It involves the analysis of music from different cultural practices in terms of the elements of music, which themselves are supposedly free from the cultural assumptions of Western art music (DES 1990), although, as a concept, they arose from the Western Avant Garde. The elements combine to represent common constructs of musical thought such as musical "devices" and "tonalities", which in turn combine to produce musical "conventions". These categories provide a framework for creating and analysing music and for representing progression in musical understanding (Garnett 2011). For example, musical devices based on rhythmic cycles can be identified in minimalist music, club dance music, West-African drumming, Gamelan; tonalities that provide systems of organising pitch can be found in Western major and minor scales, the pentatonic scales of Chinese music and the modes used in 
rock music. Whilst such an approach can result in a simplistic imposition of concepts from Western art music onto music of other cultures (Finney 2011), equally, exposure to a range of different musical processes can provide opportunities for conscious links to be made between them (Spruce 2007). To be clear: there is not an overtly articulated theory of music supporting these connections; like the concept of musical understanding itself, these connections are implicit in the curriculum documentation. What is striking about the approach to learning that is embodied in the curriculum, however, is the way in which it attempts to articulate cognitive structures and processes that underpin musical thought in its many different manifestations. On the one hand, this means that music is conceived of as a phenomenon that is itself constructed within a social context, as a form of thinking that emanates from within a particular culture (Naughton 1998). On the other hand, as Cunliffe (1998) has observed in relation to the National Curriculum for art, it means that creativity is conceived of in terms of the manipulation of cultural conventions. It is not an innate form of natural self expression, but the ability to absorb and then recombine the conventions of one or more cultures. Thus the Key Concept of Creativity within the music national curriculum is defined as, "Using existing musical knowledge, skills and understanding for new purposes and in new contexts" (QCA 2007).

Finally, assessment within the constructivist the paradigm is concerned with ascertaining the stage of cognitive development that has been reached by students, rather than their ability to perform specific tasks. On the one hand, this relies on having a model for cognitive development in music analogous to that which Piaget developed for childhood development generally (Faultey 2010); on the other, it requires a process of assessment that enables teachers to form a judgement about a student's progress against this model. The nine levels of attainment set out for music in the $\mathbf{2 0 0 0}$ curriculum (and retained largely unchanged in 2007) make no explicit reference to models of musical progression rooted in cognitive psychology (such as Hargreaves 1996) or aesthetics (Swanwick 1999). However, they do provide a model of progression that describes a continuum of cognitivemusical development that is loosely connected with age (most children are expected to reach level 2 by age 7 , level 4 by age 11 and level 5-6 by age 13. QCA 1999). Whilst open to criticism because they are too vague (QCA 2004b), too demanding (QCA 2004a), inconsistently applied (Emery et al 1998) or making questionable comparisons with progress in other subjects (Lawton 1996), the key issue for this article is that the levels provide a continuous model for how children incorporate new experiences of music into their prior understanding. They set out how pupils progress from "recognis[ing] and explor[ing] how sounds can be made and changed" at Level 1 to "identify[ing] and explor[ing] musical devices and how music reflects time, place and culture" at level 5 to 
"discriminate[ing] between and exploit[ing] the characteristics and expressive potential of selected musical resources, styles, genres and traditions" at level 8 (QCA 2007).

Assessing a pupil involves the teacher in observing what students say and do in order to build a model of their conceptual representation of music, for it is what goes on in the student's head that is of concern to the teacher (Glaserfeld 1995a). As Regelski argues (in the context of promoting a behaviourist model of teaching), conceptual learning is covert, in that it cannot be directly monitored or observed. A teacher can only "read behaviour backwards" in order to infer learning (Regelski 1986, p. 197). Glaserfeld acknowledges that this is a "fallible exercise", but maintains that it is necessary if teaching is to change a student's conceptual structures rather than simply modify their behaviour (Glaserfeld 1995a, p. 14). In order to perform this feat of inference, teachers need to draw on a range of evidence. This is partly because they need to distinguish between the quality of musical cognition in students and their proficiency at performing specific assessment tasks (Swanwick \& Franca 1999). However, it is also because the nature of musical understanding becomes increasingly complex as it progresses, so that a single task would not be adequate to demonstrate the extent of a student's ability. Thus, a student who had reached level 6 within the National Curriculum would be able to demonstrate an understanding of individual styles of music through stylistic performances, convincing pastiche composition and accurate aural analysis; whereas a student who had reached level 8 would be able to synthesise the features of musical styles and demonstrate originality in a variety of contexts, so that a single assessment exercise could only provide a partial indication of their musicianship.

\section{Critique of the constructivist curriculum}

Whilst the characteristics of the English National Curriculum described above can be regarded as strengths, there are various grounds on which it can be criticised as an exemplar of the constructivist paradigm. Its concept of musical understanding is imprecise and arguably too narrow, with insufficient awareness of an affective dimension (Finney 2011). The theoretical constructs for conceptualising the music of different cultures are imprecise and divorced from the traditions in which practising musicians learn (Garnett 2011). We have already seen that various criticisms have been made of the levels of attainment as a model for musical progression. All of these arguments address the content of the curriculum and imply that, with further effort, an improved version could be written. My concern here, however, is to question the constructivist paradigm itself as the foundation of the curriculum. I will consider three ways in which the National Curriculum for music, as an example of a constructivist curriculum, is unstable in the way that it is able to live up to its own expectations. 
First, the curriculum falls foul of an antinomy, because, while seeking to provide the opportunity for students to develop their own understanding through encounters with music, the curriculum necessarily draws on the understanding of its writers and those who teach it in order to organise and direct these encounters. These organising concepts then become taught as the content of the curriculum. Constructivist learning is predicated on students extending their mental schemata on the basis of their experience. As Regelski (1986, p. 197) puts it, "concepts are learned by students, not taught by teachers." Building a curriculum on constructivist principles aims to expose students to a series of experiences that enable them to expand their understanding of music. However, the curriculum cannot define the learning that it is seeking to direct without itself drawing on concepts to describe what is to be learned. The elements of music, for example, are a way of conceptualising music in such a way that fosters comparisons between musical genres, styles and traditions, which themselves provide a conceptual framework that shapes what students learn. As a result, there is a potential for the curriculum to be interpreted as a catalogue of concepts that students need to be taught, rather than as a framework to guide the progress of students' own process of conceptformation. Regelski expressed this by distinguishing between individual abstraction - the construction of concepts by individuals from their experience, and generalised abstraction - the use of ready-made concepts expressed through language. He argued that applying generalised abstractions to music has a deadening effect on students' experience because they are arbitrary: they are concepts that someone else has already constructed from musical experience (Regelski 1986).

The effect of this antinomy is that, instead of providing rich, musical experiences to which students apply, and hence extend, their existing mental constructs of music, activities involving composing, performing and listening become mere illustrations of specific, pre-defined, conceptually-based learning outcomes. Evidence of the effects of generalised abstraction in practice is provided by a description of a music lesson for 13-14 year olds, used by Ofsted to illustrate less-effective teaching:

Students in a Year 9 class were asked to create variations on a given sequence of notes. The teacher played a few short examples, but there was little discussion other than reinforcement of the technical devices that the students could use. They worked well and provided the required responses but were not engaged, beyond finishing the task as directed. The results showed correct use of the devices but were unimaginative. (Ofsted 2009, p. 30)

In providing "the required responses", students were demonstrating that they could reproduce the technical devices that the teacher had demonstrated to illustrate the concept of variation. The 
process of concept formation was carried out by the teacher in identifying the technical devices and in showing how the experience of listening to a set of variations could be understood in these terms. When completing the task of composing variations using these devices, the students were manipulating ready-made musical materials, derived from the teacher's cognitive engagement with music. They were learning how to perform a task correctly - essentially a piece of behavioural learning - rather than experiencing an encounter with music that prompted them to engage and expand their own concepts of how musical material can be organised. The constructivist curriculum was thus taught in a behaviourist manner, fuelled by conceptually-driven learning objectives.

A second factor that encourages the interpretation of the curriculum in this way - as concepts to be taught rather than to be abstracted by individual students from their experiences - is assessment. We have seen that the assessment of understanding involves the teacher in making inferences from a range of student activities. However, where assessment becomes focused on the outcomes of a particular task, the effect can easily be to concentrate on the student's demonstration of the particular task - their behaviour - rather than on the understanding that gives rise to the behaviour. This is a phenomenon that Black noted in relation to testing: if students are guided towards the reproduction of a narrow range of defined outcomes, "The effect is to change teaching from a constructivist back into a behaviourist style - to the detriment of sound learning." (Black 1999, p. 130). Once again, evidence is provided by Ofsted's inspections that this is happening in schools. Their 2009 report commented on the "misuse" of the National Curriculum levels to assess isolated activities (p. 31), and the 2012 report highlights the extent to which the levels are being used to assess musical behaviours rather than capturing "the 'big picture' about a student's musical responses and progress." (Ofsted 2012, p. 37). Indeed, the effect of taking a curriculum based on the constructivist paradigm and assessing it in a behaviourist way may well be more limiting than a curriculum based on a behaviourist paradigm to start with. The musical behaviours that are described in the National Curriculum level descriptors are intended to provide examples of how a given level of musical understanding might be recognised. However, if these examples are interpreted to be the substance of the level rather than merely indicators, they provide only a very limited range of behaviours for students to work towards.

The third source of instability in the constructivist curriculum is that it is taught by teachers who have undergone specialist musical training, and who have therefore come to think of themselves as musicians in terms of particular musical roles within a particular musical tradition. Whereas the National Curriculum for five-to-fourteen year olds seeks to integrate the roles of composer, performer and listener, and to develop a concept of music that is not tied to any particular tradition, 
music education from fourteen onwards develops pathways of increasing specialisation. Thus the Subject Criteria for the General Certificate of Secondary Education in music (the public examination that students can opt to take, usually at age sixteen) require the separate assessment of performing, composing and listening (OFQUAL 2011). Whilst they state that integrated approaches to teaching are to be encouraged (and one examination board sets an integrated assessment task) the criteria mark a shift in paradigm from the National Curriculum in that performing, composing and listening are assessed as discrete competencies. The experience of young people who choose to continue their music education will vary to some extent according to the tradition in which they choose to work. Matthews (2011) makes the point that jazz musicians blur the distinction between different musical roles, becoming composers, performers and listeners at different points within a set or even within a number, whereas the separation of roles is more pronounced in Western art music. Indeed, in trying to promote a broader concept of what it means to be a musician, that included teaching amongst other roles, Youth Music (2002) found that practising musicians had a tendency to narrow rather than expand their self-identity; for example thinking of themselves as a "violinist" rather than as a "performer". It is true that the process of becoming a teacher involves developing pedagogical knowledge and skills, including an element of meta-cognition. This enables the teacher to translate their expertise in music into learning experiences in music, distinguishing this role at least to some extent from that of being a musician (Ferm 2008). Indeed, Hargreaves et al (2007) suggests that the extent to which the developing identity of a classroom teacher differs from that of a musician itself contributes to the lack of authentic classroom experiences of music. Nevertheless, the integration of performing, composing and listening, the neutral cultural position expressed in terms of the elements of music, and assessment based on a loosely-defined model of cognitive musical development together represent a model of music education that even younger teachers are unlikely to have encountered since the age of fourteen, when they began their post-compulsory study of music. In order to teach this model, they must effect a translation of their experience as musicians into the conceptual structures of the National Curriculum. It is perhaps not surprising if some teachers are more successful in doing this than others; nor if, for some, the qualities that make them musicians become obscured in the process of translation. That this is the case is apparent from Ofsted's comments on the unmusical teaching that was observed in some schools: "Too much use was made of verbal communication and non-musical activities. Put simply, in too many cases there was not enough music in music lessons." (Ofsted 2012 p. 4)

The collapse of a curriculum based on constructivist principles into behaviourist teaching is not inevitable: the National Curriculum arose out of the successes of educators such as Paynter and Swanwick, and Ofsted's inspections of schools in England recognise good and outstanding teaching 
as well as the satisfactory and inadequate. However, there is evidence that the constructivist curriculum is not robust. Concepts that serve to organise the curriculum easily become transferred to the content of the curriculum. Behaviours that provide evidence of understanding can easily become defined outcomes of a task. Teachers can struggle to express their own musicianship within the parameters defined by the curriculum. When this occurs, not only does the constructivist curriculum collapse to form a behaviourist model, but it becomes a very narrow behaviourist model because it is based upon concepts that are generalised abstractions from musical experience. Whilst it is not inevitable that a constructivist curriculum will be interpreted in a behaviourist way, guiding students so that they form their own, individualised abstractions can be a delicate process that requires the student's active and willing participation (Black 1999). Likewise, assessing a student's cognitive development requires the teacher to make potentially-fallible inferences from behaviour (Glaserfeld 1995a) rather than direct observations. It is therefore perhaps not unlikely or unsurprising, given the pressures under which teachers work, if a constructivist curriculum does behave in an unstable way and become dominated by talk rather than focusing on the musical quality of students work (Ofsted 2012).

\section{Beyond a constructivist curriculum}

We have seen that the rise of the constructivist paradigm in music education characterised instrumental tuition as behaviourist training, but that this is not necessarily the case. We have also seen that the National Curriculum in England, which is based on the constructivist paradigm, can result in teaching that is distinctly behaviourist in character. Four implications arise from this.

First, there is a distinction to be made between the paradigm in which a curriculum is grounded and that of the pedagogy that is used to teach it. A curriculum predicated on learning to play an instrument or learning to compose can be taught in a behaviourist way that focuses on acquiring skills as behaviours, or in a constructivist way that seeks to develop a particular musical competency as an expression of an underlying understanding of music. Equally, a curriculum predicated on developing an understanding of music can be taught in a manner that extends the student's cognitive engagement with music, but it can also be taught in a way that focuses on the reproduction of a narrow range of behaviours. A constructivist curriculum does not ensure a constructivist pedagogy.

Second, it is the separation of musical thinking and musical making that results in the narrowing of musical learning. On the one hand, a focus solely on music-making can result in a valuing of technique as an end in itself without a connection to the musical purpose of technique. This can be 
seen in Reid's (2001) analysis of conservatoire students and in Paynter's critique of tutoring in skills and proficiencies at the expense of creativity (Paynter 1982). On the other hand, musical thinking, if separated from authentic music making, can become an exercise in illustrating empty concepts rather than an opportunity for individuals to expand their own cognitive capacity. This was apparent in Regelski's analysis of individual and generalised abstractions and in Ofsted's descriptions of unmusical, concept-driven teaching (Ofsted 2012). Only by combining musical making and musical thinking does the opportunity arise for individuals to construct their own understanding of music, and for this understanding to be rooted in the experience of sound. Without an authentic experience of music, there is nothing for a student to understand.

Third, an important factor in designing a curriculum is its robustness. It appears that a curriculum built on a constructivist paradigm but taught in a behaviourist way is, if anything, more narrow than a curriculum conceived of in behaviourist terms. Not only does a constructivist curriculum depend upon teachers correctly interpreting the concept of musical understanding on which it is based (which the literature has demonstrated is by no means straightforward), but it requires teachers to remain focused on the development and assessment of long-term cognitive goals rather than shortterm behaviour-based success criteria. Without these conditions, there is a danger that lessons would resemble those highlighted in Ofsted's reports in which there is no making of music beyond a limited demonstration of isolated concepts. A curriculum based on a behaviourist paradigm may prove more robust. If taught using a constructivist pedagogy, this curriculum could provide a basis in music making that would allow students to develop their musical thinking. Even if it were taught using a behaviourist paradigm, however, such a curriculum would at least provide an experience of music making from which the students might draw their own conclusions despite the efforts of their teacher.

Fourth, it should be acknowledged that, although the constructivist paradigm is not synonymous with the teaching of a curriculum based on creativity - we have seen that it is possible to teach performance in a constructivist way - creativity nevertheless plays an intrinsic role in a constructivist approach to teaching. Whether learning to play the violin, learning to compose or learning the conventions of Samba music, creativity represents the difference between copying a sequence of behaviours and internalising the processes that are at work. It is a mode of exploration that brings together music-making and musical thinking. It is the means by which knowledge developed from one set of circumstances is applied to a new situation, and thus developed into understanding. Quite apart from being an important element of content in a music curriculum, creativity is integral to the way any music curriculum is to be taught, if it is to draw upon a constructivist pedagogy. 


\section{Conclusion}

The starting point for this article was the apparent fault line in music education between the teaching of performance and the teaching of "music" in a wider sense. Whilst this distinction encompasses a range of issues to do with institutions, aesthetics and content, fundamentally it represents an ideological difference between a paradigm of musical training based on learning specific musical behaviours and one of musical education based on developing an understanding of music. In England, the National Curriculum for music studied by children aged 5 to 14 has defined learning according to the constructivist paradigm of education, whereas extra-curricular activities, including instrumental and vocal tuition, have been defined in terms of the musical behaviours that they represent - as has post-compulsory education in music from age 14. The result has been a discontinuity between the espoused aims of the 5-14 compulsory curriculum to do with musical understanding and the focus on musical competency for those who choose to specialise in music. At the same time, the introduction of whole-class instrumental and vocal tuition $n$ England has made apparent in the classroom what had already been known in the conservatoire studio, that the teaching of performance need not be a behaviourist enterprise. This apparent fault line in curriculum can thus be evaded through continuity in pedagogy. Creative teaching for musical understanding is possible through a curriculum of learning the violin just as it is through the study of musical traditions through the integration of performing, composing and listening.

However, what is perhaps a more significant fault line has emerged: that between the espoused aims of the 5-14 curriculum conceived in terms of constructivist learning, and the enacted curriculum which is often delivered in a behaviourist way. (A more thoroughgoing analysis of ideological fracture between espoused and enacted policy in relation to the history curriculum can be found in Harris \& Burn 2011.) The effect of this is for concepts that have been abstracted from musical experience to be taught as if they were musical behaviours. The result is not only a behaviourist pedagogy that teaches concepts based on the elements of music as if they were skills, but one that gives students experiences of music that are constrained by the need to exemplify concepts, rather than presenting a rich, musical experience.

Darren Henley's review of music education in England (Henley 2011) has resulted in a National Plan for Music Education that, on the one hand recognises the need to fund aspects of music education that are beyond the capability of individual schools to provide, and on the other, promotes better integration of in-school and out-of-school opportunities (DoE 2011). In order for this integration to succeed, it will be necessary for the compulsory school curriculum to define learning in a way that is consistent with the competency-based model that is used in post-compulsory curricula and in out- 
of-school contexts. Children will need to become musicians through developing their competency in composing, performing and listening to music. Equally, however, the quality of the teaching both in and out of school will depend on the development of high-quality, constructivist pedagogy, that reflects the way in which children learn. "Constructivism does not claim to have made earthshattering inventions in the area of education, it merely claims to provide a solid conceptual basis for some of the things that, until now, inspired teachers had to do without theoretical foundation" (Glaserfeld 1995a, p. 15). For music, this includes the recognition that musical creativity is a central part of musical understanding, and is of vital importance, regardless of the curriculum content.

6926 words 


\section{References}

BAMFORD, A. AND P. GLINKOWSKI (2010). Wow, it's music next: Impact evaluation of the Wider Opportunities Programme in music at Key Stage Two. Leeds: Federation of Music Services

BLACK. P. (1999) Assessment, learning theories and testing systems. In P. Murphy (Ed.) Learners, learning and assessment. London: Paul Chapman (118 -134)

COX, G. (2001). "A House Divided?" Music education in the United Kingdom during the Schools Council era of the 1970s. Journal of Historical Research in Music Education 22:2, 160-175

CUNLIFFE, L. (1998). Art and art education as a cognitive process. In R. Burden \& M. Williams (Ed.) thinking through the curriculum. London: Routledge (47-71)

DCSF (2007) The National Curriculum. London: Department of Children, Schools and Families and Qualifications and Curriculum Development Authority

DES (1990). National Curriculum music working group interim report. London: Department of Education and Science

DES (1992). Music in the National Curriculum. London: Department of Education and Science DFEE (1995). National Curriculum for music. London: Department for Education and Employment DfE (2011) The importance of music - a national plan for music education. London: Department for Education. Available at www.education.gov.uk/publications/standard/publicationDetail/Page1/DFE00086-2011 (Accessed 21/6/12)

DEARING, R. (1994). The National Curriculum and its assessment: Final report. London: SCAA

EMERY. H., J. WILMOT \& R. MURPHY (1998). Consistency in teacher assessment and the impact of SCAA guidance materials at key stage 3 in the non-core subjects: Report to QCA. Nottingham: School of Education, University of Nottingham

FAUTLEY, M. (2010) Assessment in music education. Oxford: Oxford University Press

FERM, C. (2008). Playing to teach music - embodiment and identity-making in musikdidaktik. Music Education Research. 10:3, 361-372.

FINNEY, J. (2011). Music education in England 1950 - 2010: The child-centred progressive tradition. Aldershot: Ashgate

GARNETT, J. (2011). Thinking the music of the future: The music theory of the National Curriculum. NAME Magazine. 33, 5-8

GLASERFELD, E. (1995a). A constructivist approach to teaching. In L.P. Steffe\& J. Gale (Ed.)

Constructivism in Education. Hillsdale, NJ: Lawrence Erlbaum Associates Inc.

GLASERFELD, E. ( 1995b) Radical Constructivism. London: Falmer 
GRIFFIN, L.L. \& K. PATTON (2005). Two Decades of Teaching Games for Understanding: Looking at past, present and future. In L.L. Griffin \& J.I. Butler (Ed.) Teaching Games for Understanding.

Champaign II: Human Kinetics

HARGREAVES, D.J. (1996). The development of artistic and musical competence. In I. Deliége \& J. Sloboda (Ed.) Beginnins: Origins and development of musical competence. Oxford: Oxford University Press

HARGREAVES, D.J., R.M. PURVES, G.F. WELCH \& N.A. MARSHALL (2007). Developing identities and attitudes in musicians and classroom music teachers. British Journal of Education Psychology. 77:3, 665-682.

HARRIS, R. \& K. BURN (2011) Curriculum theory, curriculum policy and the problem of ill-disciplined thinking. Journal of Education Policy 26:2, 245-261.

HENLEY, D. (2011). Music Education in England - A Review by Darren Henley for the Department for Education and the Department for Culture, Media and Sport. London: Department for Education. Available at www.education.gov.uk/publications/standard/AllPublications/Page11/DFE-00011-2011. Accessed 21/6/12

LAWTON, D. (1996). Beyond the National Curriculum: Teacher professionalism and empowerment. London: Hodder \& Stoughton

MATTHEWS, F. (2011). Adopting an integrated approach to musical learning in whole class instrumental and vocal lessons. In N.Beach, J. Evans \& G. Spruce (ED.) Making music in the primary school. London: Routledge (66-73)

NAUGHTON, C. (1998). Thinking about and through music. In R. Burden \& M. Williams (Ed.) Thinking through the curriculum. London: Routledge (72-83)

NATIONAL STRATEGY (2006). KS3 music: A professional development programme. Available at http://www3.hants.gov.uk/music. Accessed 21/6/12.

ODAM, G. (1995). The sounding symbol: Music education in action. Cheltenham: Stanley Thornes

OFSTED (2009). Making more of music: An evaluation of music in schools 2005-2008. London: Ofsted. Available at http://www.ofsted.gov.uk/resources/making-more-of-music-evaluation-of-musicschools-2005-08. Accessed 21/6/12

OFSTED (2012). Music in schools: wider still, and wider. London: Ofsted. Available at http://www.ofsted.gov.uk/resources/music-schools-wider-still-and-wider. Accessed 21/6/12

PAYNTER, J. (1982). Music in the secondary school curriculum. Cambridge: Cambridge University Press

PAYNTER, J. \& P. ASTON (1970) Sound and Silence Cambridge: Cambridge University Press

PAYNTER, J. (1997) The form of finality: a context for music education. British Journal of Music Education. 14:1, 5-21 
PITTS, S. (2000). A century of change in music education. Aldershot: Ashgate

QCA (1999) The National Curriculum: Music. London: Qualifications and Curriculum Authority

QCA (2004a) Music: 2002/3. Annual report on curriculum and assessment. London: Qualifications and Curriculum Authority

QCA (2004b) Music: 2003/4. Annual report on curriculum and assessment. London: Qualifications and Curriculum Authority

OFQUAL (2011). Subject criteria for GCSE music. London: Office of Qualification and Examination Regulation. Available at http://www.ofqual.gov.uk/downloads/category/192-gcse-subject-criteria. Accessed 21/6/12.

REGELSKI, T.A. (1986). Concept learning and action learning in music education. British Journal of Music Education 3:2, 185-216

REID, A. (2001). Variations in the ways that instrumental and vocal students experience learning music. Music Education Research. 3:1, 25 - 40.

SOLOMAN, P.G. (2003). The Curriculum Bridge. California: Curwen Press Inc.

SPRUCE, G. (2007). Culture, society and musical learning. In C. Philpott \& G. Spruce (Ed.) Learning to teach music in the secondary school. (Second Edition). London: Routledge

SPRUCE, G. (2011). Integration: Setting the scene. In N. Beach, J. Evans \& G. Spruce (Ed.) Making music in the primary school. London: Routledge (63-65)

SWANWICK, K. (1979). A basis for music education. London: NFER

SWANWICK, K. (1999). Teaching music musically. London: Routledge

SWANWICK, K. \& D. TAYLOR (1982). Discovering music. London: Batsford

SWANWICK, K. \& FRANCA, C.C. (1999). Composing, performing and audience-listening as indicators of musical understanding. British Journal of Music Education. 16:1, 5-19.

WILLIAMS, M. \& R. BURDEN (1998) Pulling it together: The challenge for the educator. In R. Burden \& M. Williams (Ed.) Thinking trough the curriculum. New York: Routledge

YOUTH MUSIC (2002) Creating a land with music. Available at http://www.youthmusic.org.uk/assets/files/HEFCEreport1.pdf. Accessed 21/6/12 